\title{
Engineering Attributes of Buckwheat Seeds in Relation to its Moisture Content
}

\author{
M. Mohammad Sohail and S. K. Satpathy* \\ Department of Farm Machinery and Power Engineering, College of Agricultural Engineering \\ and Post Harvest Technology (CAU, Imphal), Gangtok, Sikkim, India \\ *Corresponding author
}

\section{A B S T R A C T}

\section{Keywords}

Buckwheat Seeds, Moisture Content, Farm machineries

\section{Article Info}

\section{Accepted:}

15 December 2020 Available Online: 10 January 2021
Design of any farm machineries like thresher, conveyor, seed drills, harvester, and processing equipments, requires a thorough understanding of the engineering properties of seeds. The engineering properties of seeds also vary with moisture content of the seeds. In this study, the effect of moisture content on engineering properties of buckwheat seeds was studied. Total of fourteen properties were examined at three different moisture content levels i.e., $16 \%, 18 \%$ and $20 \%$ (d.b.). It was observed that the value of physical properties viz., length, width, thickness, geometric mean diameter, arithmetic mean diameter, surface area, sphericity increased with the increase in moisture content. The thousand seeds weight increased with moisture content but the densities were found to decrease with increase in moisture content, indicating higher rate of volume expansion due to moisture absorption by the seed. The engineering properties such as angle of repose decreased, while the terminal velocity increased with increase in the moisture content. However, the static friction co-efficient were found to slightly increase but the effect of moisture content was not significant within the studied moisture range. The above study provides vital information for design and development of machine for efficient post harvest operation of buckwheat seeds.

\section{Introduction}

Buckwheat belongs to a pseudo cereal family and its seeds are consumed as seeds. Buckwheat is a highly nutritious whole seeds, which is a rich source of protein, fiber, and energy. Buckwheat flour is gluten free, thus it is an excellent dietary alternative. The cultivation of buckwheat in hilly regions of Northeast India has been increasing considerably (Annual Report, FS \& AD, Government of Sikkim, 2017) in the last decades. Presently, threshing of buckwheat is done in traditional ways i.e., foot trampling and hand beating which results in high percentage of losses due broken and damaged seeds. The traditional method also results in low level of seeds separation, high damage to kernels, other losses and also it is very time and high labour intensive. Thus, suitable machineries for efficient post harvest operation of Buckwheat are the need of the hour. The design and development of farm machine for post harvest processing and 
storage of buckwheat requires information about the various engineering properties viz., dimensional, gravimetric, frictional, aerodynamic properties etc. Moisture content is one of the important parameter to be considered while designing and developing machineries for crops (Tabatabaeefar, 2003). Dimensional properties such as length width, thickness are used for selection of sieve separators (size of screen opening), and concave grade opening size in threshers. The gravimetric properties like bulk density, true density and porosity plays a vital role for the design of hopper, clean seeds collection chamber for the machines etc. The angle of repose is important for design of appropriate hopper or feeding chute or inclination of the channel. The frictional properties of the seeds against the various surfaces are also necessary for selection of material in designing of thresher, handling and storing structures. These engineering properties of also dependent on the moisture content and change with the change in moisture content of seeds.

The main objective of this study was to determine the engineering properties of buckwheat seeds at various levels of moisture content and study the effects of moisture content on various engineering properties.

\section{Materials and Methods}

\section{Sample preparation and experimental setup}

The buckwheat seed Fig. 1 (var. Meethey) was procured from the local market in Gangtok, Sikkim. Based on preliminary assessment of collected seed samples the moisture content was found to be $15.2 \%$. The seeds moisture contents at the time of harvest usually are as high as $20-22 \%$. Therefore, the seeds are moisture conditioned to three moisture levels within the range 15-22\%. The seeds samples were conditioned to the desired moisture content level by adding calculated amount of distilled water in accordance to Eq.1 (Sologubik et al., 2013) and mixing thoroughly while enclosing the sample in a self sealing polyethylene bag. The seeds samples in polyethylene bags were then kept in shade for minimum of one week before the experiments so that the seeds can reach to the new uniform moisture content level.

$$
Q=\frac{B_{i}\left(M_{f}-M_{i}\right)}{M_{i}+100}
$$

Where, $B_{i}$ is initial mass of the sample in $\mathrm{kg}$; $\mathrm{M}_{\mathrm{i}}$ and $\mathrm{M}_{\mathrm{f}}$ are the initial and final (desired) moisture content of sample in \% (dry basis) and Q is the mass of water to be added in $\mathrm{kg}$.

The moisture contents selected for the study of engineering properties of the buckwheat seeds were $16 \%, 18 \%$ and $20 \%$ d.b. All tests were conducted in the laboratory at ambient temperature of about $20-22^{\circ} \mathrm{C}$ and relative humidity of $55-65 \%$.

\section{Measurement procedure}

\section{Dimensions}

In the study length was defined as the largest dimension of the seeds while the width as the longest dimension in an axis perpendicular to that of the length. The thickness was taken to be the largest dimension along a third axis perpendicular to both the length and width. A digital Vernier calliper measuring to an accuracy of $0.005 \mathrm{~mm}$ was used to measure the length, width and thickness of 100 seed randomly selected from each sample. Geometric mean diameter $\left(D_{g}\right)$, arithmetic mean diameter $\left(D_{a}\right)$, sphericity $\left(S_{p}\right)$, surface Area $(A)$ and volume $(V)$ were determined from the principal dimensions using the following Eq. (2), (3) (4), (5), and (6) respectively (Tabatabaeefar, 2003). 


$$
\begin{aligned}
& D_{g}=(L W T)^{\frac{1}{a}} \ldots \\
& D_{a}=\frac{(L+W+T)}{3} \\
& S_{p}=\frac{\left(D_{g}\right)}{L} \cdot . \\
& A=\pi D_{g}^{2} . \\
& V=0.25\left(\frac{\pi}{6} \times L(W+T)^{2}\right)
\end{aligned}
$$

Where, $D_{g}$ : Geometric mean diameter, mm; $D_{a}$ : Arithmetic mean diameter, $\mathrm{mm} ; S_{p}$ : Sphericity,

A: Surface Area, $\mathrm{mm}^{-2} ; V:$ Volume, $\mathrm{mm}^{-3} ; L$ : Length, mm; W: Width, mm; T: Thickness, $\mathrm{mm}$.

\section{Thousand seeds weight}

A seeds mass of approximately $1 \mathrm{~kg}$ was roughly divided into 10 equal parts and then 100 seeds were taken from each portion. The 1000 seeds thus picked were combined into a single batch and weighed using a digital electronic balance reading to an accuracy of $0.001 \mathrm{~g}$. The measurement was repeated five replications. The average of the five measurements reported as the 1000 seeds weight (Coskun et al., 2006).

\section{Density and porosity}

The bulk density of seeds was determined by pouring the seeds in to a $500 \mathrm{ml}$ container from a height of $15 \mathrm{~cm}$ using a funnel and then weighing the mass of seeds filled in the container (Bart-plange and Baryer, 2003). The measurement was repeated five times and the mean mass was calculated. The bulk density was then calculated by dividing the mean mass $(\mathrm{kg})$ by the volume $\left(\mathrm{m}^{3}\right)$. The toluene $\left(\mathrm{C}_{7} \mathrm{H}_{8}\right)$ displacement method as outlined by
Karimi et al., 2009 was followed to determine the true density of the seeds by $\operatorname{Eq}(8)$. True density was calculated as the ratio of mass of sample in air to volume of displaced toluene $\left(\mathrm{C}_{7} \mathrm{H}_{8}\right)$.

$$
\begin{aligned}
& \rho_{b}=\frac{m}{v} \ldots(7) \\
& \rho_{t}=\frac{m}{v_{t}}
\end{aligned}
$$

Where, $\rho_{b \text { : }}$ bulk density, $\mathrm{kg} . \mathrm{m}^{-3} ; \rho_{t}$ : true density, $\mathrm{kg} \cdot \mathrm{m}^{-3} ; m$ : mass of sample, $\mathrm{kg} ; V=$ volume of the container, $\mathrm{m}^{3}$ and $V_{t}$ : volume of the toluene displaced by the sample, $\mathrm{m}^{3}$.

The porosity was calculated from the measured values of bulk density and true density using the relationship given by Karimi et al., 2009. This relationship is presented in form of Eq. (9).

$$
\varepsilon_{p}=\left(1-\frac{\rho_{b}}{\rho_{t}}\right) \times 100
$$

Where, $\varepsilon$ : porosity, \%; pb: bulk density, kg.m ${ }^{3}$ and $\rho_{t}$ : true density, kg. $\mathrm{m}^{-3}$.

\section{Angle of repose}

An open ended cylinder of $3.75 \mathrm{~cm}$ diameter and $25 \mathrm{~cm}$ height was placed on a flat plate and then filled with seeds.

The cylinder was raised slowly so that the samples formed a cone on the flat plate as shown in Fig. 2. The height and diameter of the cone was measured and the angle of repose was calculated by the following relationship Eq (10).

$$
\theta=\tan ^{-1}\left[\frac{2 H}{D}\right]
$$

Where, $\theta$ : angle of repose, degrees; $H$ : height of the cone, $\mathrm{mm} ; D$ : diameter of the cone, $\mathrm{mm}$ 


\section{Static coefficient of friction}

The static coefficient of friction $(\mu)$ of buckwheat was determined by the displacement of seeds on four different surface, plywood, aluminium, mild steels and galvanized iron. Seeds filled in a square box were placed on a tilting top table. The table top was tilted slowly and the tilt angle was measured at which the seed box starts moving. The tilting table top is shown in Fig 3 . The coefficient of friction was calculated as the tangent of the angle measured (Sahay and Singh, 2009).

$$
\mu=\tan \alpha
$$

Where, $\mu$ : static coefficient of friction; $\alpha$ : Angle of tilt.

\section{Terminal velocity}

The terminal velocity of the buckwheat samples was measured using an air column. A sample was dropped into the airstream from the top of the air column, and air was blown up the column to suspend the material in the airstream.

The minimum air velocity at which the seeds remained in suspension was measured using a digital anemometer. The terminal velocity measurement setup is shown in Fig. 4. Average value of five replications was reported.

\section{Statistical analysis}

The results obtained from physical and engineering properties at three different moisture contents $(16 \%, 18 \%$ and $20 \%$ d.b.) were subjected to analysis of variance (ANOVA) and Duncan Multiple Range Test (DMRT) using SPSS 21.0 software and linear regression analysis, using Microsoft Excel 2007.

\section{Results and Discussion}

\section{Seeds dimensions and size}

The dimensional properties at measured at moisture contents from 16 to $20 \%$ (d.b) is presented in Table-1. With increasing moisture content from 16 to $20 \%$ d.b, length $(\mathrm{L})$, width $(\mathrm{W})$, thickness $(\mathrm{T})$, the geometric mean diameter $(\mathrm{Dg})$, arithmetic mean diameter (Da), surface area and sphericity of seeds increased significantly $(\mathrm{p}<0.05)$ from 5.59 to $5.62 \mathrm{~mm}, 3.80$ to $4.03 \mathrm{~mm}, 3.44$ to $3.62 \mathrm{~mm}, 4.18$ to $4.35 \mathrm{~mm}, 4.28$ to $4.43 \mathrm{~mm}$, 54.90 to $59.33 \mathrm{~mm}^{2}, 0.75$ to 0.77 and 14.89 to $15.57 \mathrm{~mm}^{-3}$ respectively (Fig.5). The increase in size could be attributed due to the expansion of the seeds as a result of moisture absorption in the void spaces inside the seeds (Solomon and Zewdu, 2009). The dependence of these properties with moisture content (M) could be represented by the following equations. A similar trend has been reported for wheat, barley seeds (Tabatabaeefar, A. 2003; Sologubik, et al., 2013).

$$
\begin{array}{cc}
L=0.035 M+5.54 & \left(R^{2}=0.942\right) \\
W=0.115 M+3.723 & \left(R^{2}=0.750\right) \\
T=0.095 M+3.373 & \left(R^{2}=0.789\right) \\
D_{g}=0.085 M+4.206 & \left(R^{2}=0.836\right) \\
D_{\alpha}=0.09 M+4.113 & \left(R^{2}=0.832\right) \\
V=0.84 M x+13.91 & \left(R^{2}=0.926\right)
\end{array}
$$

\section{Sphericity}

The values of sphericity $\left(S_{p}\right)$ were calculated individually by Eq. (4) using the data from the geometric mean diameter and the length of the seeds of buckwheat. The results are presented in Table 1. The sphericity increased significantly from 0.75 to $0.80(\mathrm{p}<0.05)$ when the moisture content increased from $16 \%$ to $20 \%$ (d.b).

The initial increase in the sphericity may be attributed due to proportional increased in the 
length, width and thickness. The relationship between moisture content and the sphericity $\left(S_{p}\right)$ of the seeds can be represented by the following equation:

$S_{p}=0.025 M+0.726 \quad\left(R^{2}=0.98\right)$

Increase in sphericity with increase in moisture was also observed in case of wheat, barley seeds and cocao beans (Tabatabaeefar, 2003; Sologubik, et al., 2013, Bart-Plange and Baryeh, 2003).

\section{Volume}

The volume of seeds significantly ( $<<0.05$ ) increased from 23.74 to $24.082 \mathrm{~mm}^{-3}$ as moisture content increased from 16 to $20 \%$ d.b. as observed from the Table-1. The following equation can be used to describe the relationship of volume with moisture content of seeds.

\section{$V=0.84 M+13.91 \quad\left(R^{2}=0.926\right)$}

\section{Surface area}

The buckwheat surface area (A) significantly $(p<0.05)$ increased from $54.96 \mathrm{~mm}^{2}$ to 59.33 $\mathrm{mm}^{2}$ with increase in moisture content from 16 to $20 \%$ d.b. as observed from Table 1 .

The increasing trend of surface area of buckwheat seeds with moisture content is represented in Fig. 6. The relationship between moisture content and the surface area (A) of the seeds can be represented by the following equation:

$A=2.2 M+53.1 \quad\left(R^{2}=0.909\right)$

Similar trends have been reported for guna seeds and neem nut (Aviara, N. A., et al., 1999; Visvanathan, R et al., 1996).

\section{Weight of thousand seeds}

The results of one thousand seed weight are presented in Table-2. The variation of the weight of thousand seeds $\left(\mathrm{w}_{1000}\right)$ is shown in Fig. 7. The $\mathrm{W}_{1000}$ increased significantly $(\mathrm{p}<$ 0.05 ) linearly from 23.75 to $24.08 \mathrm{~g}$ as the moisture content increased from 16 to $20 \%$ d.b. The relationship between moisture content and weight of thousand seeds can be represented by the following regression equation:

$$
W_{1000}=0.167 M+23.57 \quad\left(R^{2}=0.990\right)
$$

Similar behaviours were also reported for buckwheat, green wheat, sweet corns seeds (Latha Rani, R and Uma N. Kulkarni. 2020; Al-Mahasneh and Rababah, 2007; Coşkun, M. B. et al., 2006).

\section{Bulk density}

The results of bulk density are presented in Table-2. Bulk density $\left(\rho_{b}\right)$ of the buckwheat seeds at different moisture levels varied significantly ( $p<0.05$ ) from 541.46 to 513.77 $\mathrm{kg} \cdot \mathrm{m}^{-3}$ when moisture content increased from $16 \%$ to $20 \% \mathrm{db}$ (Fig. 8). This behaviour could be attributed to the fact that the rate of increase in mass of the sample associated with increased moisture was less than the corresponding rate of volume expansion of seeds due to moisture absorption. This resulted in more inter-seeds voids in the wetter seeds than the drier seeds. The relationship of bulk density $\left(\rho_{b}\right)$ of buckwheat seeds with moisture content can be expressed by the following equation:

$\rho_{b}=-13.84 M+552.0 \quad\left(\mathrm{R}^{2}=0.859\right)$

A similar trend has been reported for various materials like guna seeds, okra seeds and barley (Aviara et al., 1999, Sahoo, P. K., and Srivastava, A. P. 2002) 


\section{True density}

The results of true density are presented in Table-2. The true density $\left(\rho_{t}\right)$ of buckwheat seeds showed a significant $(\mathrm{p}<0.05)$ decrease from 1067 to $936.60 \mathrm{~kg} \mathrm{~m}^{-3}$ when moisture content changed increased from 16 to $20 \% \mathrm{db}$ (Fig. 9). In view of the fact that the true density relates to the seeds mass contained in a seeds volume, the observed reduction on $\rho_{t}$ could be explained by the fact that the increment of seeds weight caused by the moisture gain was proportionally less than the volume expansion of seeds. Similar results were also reported for sorghum (Mwithiga and Sifuna, 2006). The moisture dependence of true density can be represented by the following regression equation.

$$
\rho_{t}=-65.15 M+1110 \quad\left(\mathrm{R}^{2}=0.760\right)
$$

Table.1 Dimensional properties of buckwheat seeds at different levels of moisture content

\begin{tabular}{|c|c|c|c|c|c|c|c|c|}
\hline $\begin{array}{c}\text { MC } \\
(\mathbf{\%}, \mathbf{d . b})\end{array}$ & $\begin{array}{c}\text { Length } \\
(\mathbf{m m})\end{array}$ & $\begin{array}{c}\text { Width } \\
(\mathbf{m m})\end{array}$ & $\begin{array}{c}\text { Thickness } \\
(\mathbf{m m})\end{array}$ & $\begin{array}{c}\boldsymbol{D}_{\boldsymbol{g}} \\
(\mathbf{m m})\end{array}$ & $\begin{array}{c}\boldsymbol{D}_{\boldsymbol{a}} \\
(\mathbf{m m})\end{array}$ & $\begin{array}{c}\boldsymbol{S p} \\
(\mathbf{m m})\end{array}$ & $\begin{array}{c}\boldsymbol{A} \\
\left(\mathbf{m m}^{-\mathbf{2}}\right)\end{array}$ & $\begin{array}{c}\text { Volume } \\
\left(\mathbf{m m}^{\mathbf{3}}\right)\end{array}$ \\
\hline $\mathbf{1 6}$ & $5.59^{\mathrm{a}}$ & $3.44^{\mathrm{a}}$ & $3.44^{\mathrm{a}}$ & $4.18^{\mathrm{a}}$ & $4.28^{\mathrm{a}}$ & $0.75^{\mathrm{a}}$ & $54.90^{\mathrm{a}}$ & $64.39^{\mathrm{a}}$ \\
& $(0.57)$ & $(0.34)$ & $(0.34)$ & $(0.37)$ & $(0.37)$ & $(0.06)$ & $(9.62)$ & $(29.01)$ \\
\hline $\mathbf{1 8}$ & $5.49^{\mathrm{a}}$ & $4.03^{\mathrm{b}}$ & $3.62^{\mathrm{b}}$ & $4.31^{\mathrm{b}}$ & $4.38^{\mathrm{ab}}$ & $0.78^{\mathrm{ab}}$ & $58.47^{\mathrm{b}}$ & $164.39^{\mathrm{b}}$ \\
& $(0.60)$ & $(0.65)$ & $(0.44)$ & $(0.42)$ & $(0.41)$ & $(0.09)$ & $(11.81)$ & $(29.01)$ \\
\hline $\mathbf{2 0}$ & $5.62^{\mathrm{a}}$ & $4.07^{\mathrm{b}}$ & $3.62^{\mathrm{b}}$ & $4.35^{\mathrm{b}}$ & $4.42^{\mathrm{b}}$ & $1.12^{\mathrm{b}}$ & $60.01^{\mathrm{b}}$ & $264.39^{\mathrm{c}}$ \\
& $(0.53)$ & $(0.59)$ & $(0.46)$ & $(0.44)$ & $(0.44)$ & $(0.06)$ & $(12.49)$ & $(29.01)$ \\
\hline
\end{tabular}

The values in parenthesis are standard deviations

Values in the same column with different subscripts $(\mathrm{a}-\mathrm{c})$ are significantly different $(\mathrm{p}<0.05)$ from DMRT

Table.2 Gravimetric properties of buckwheat seeds at different levels of moisture content

\begin{tabular}{|c|c|c|c|c|}
\hline M.C\% & $\begin{array}{l}\text { One thousand } \\
\text { seed mass (g) }\end{array}$ & $\begin{array}{l}\text { Bulk density } \\
\left(\mathrm{kg} \cdot \mathrm{m}^{-3}\right)\end{array}$ & $\begin{array}{c}\text { True density } \\
\left({\left.\mathrm{kg} . \mathrm{m}^{-3}\right)}^{-3}\right.\end{array}$ & $\begin{array}{c}\text { Porosity } \\
(\%)\end{array}$ \\
\hline 16 & $23.74 \pm 1.94^{\mathrm{a}}$ & $541.46 \pm 0.01^{\mathrm{a}}$ & $1064.4 \pm 0.05^{\mathrm{a}}$ & $49.26 \pm 3.08^{\mathrm{a}}$ \\
\hline 18 & $23.90 \pm 0.13^{\mathrm{a}}$ & $517.93 \pm 0.01^{\mathrm{ab}}$ & $930 \pm 0.09^{\mathrm{a}}$ & $45.09 \pm 6.47^{\mathrm{a}}$ \\
\hline 20 & $24.08 \pm 0.39^{\mathrm{a}}$ & $512.77 \pm 0.02^{\mathrm{b}}$ & $928.1 \pm 0.10^{b}$ & $44.60 \pm 6.64^{\mathrm{a}}$ \\
\hline
\end{tabular}

Values in the same column with different subscripts $(\mathrm{a}-\mathrm{c})$ are significantly different $(\mathrm{p}<0.05)$ from DMRT

Table.3 Frictional and aerodynamic properties of buckwheat seeds with moisture content

\begin{tabular}{|c|c|c|c|c|c|c|}
\hline \multirow[t]{2}{*}{ MC \% } & \multirow{2}{*}{$\begin{array}{c}\text { Angle of } \\
\text { repose } \\
\theta\left({ }^{\circ}\right)\end{array}$} & \multicolumn{4}{|c|}{ Coefficient of static friction, $\mu$} & \multirow{2}{*}{$\begin{array}{l}\text { Terminal } \\
\text { velocity, } \\
v\left(\mathrm{~m}^{-1} \mathrm{~s}^{-1}\right)\end{array}$} \\
\hline & & $\mathrm{Al}$ & GI & PW & MS & \\
\hline 16 & $30.64 \pm 1.16^{\mathrm{a}}$ & $0.39 \pm 0.01^{\mathrm{a}}$ & $0.45 \pm 0.01^{\mathrm{a}}$ & $0.42 \pm 0.05^{\mathrm{a}}$ & $0.44 \pm 0.01^{\mathrm{a}}$ & $3.22 \pm 0.08^{\mathrm{a}}$ \\
\hline 18 & $28.72 \pm 3.42^{\mathrm{ab}}$ & $0.41 \pm 0.03^{\mathrm{a}}$ & $0.46 \pm 0.01^{\mathrm{a}}$ & $0.40 \pm 0.04^{\mathrm{a}}$ & $0.43 \pm 0.06^{\mathrm{a}}$ & $3.12 \pm 0.08^{\mathrm{a}}$ \\
\hline 20 & $25.93 \pm 1.99^{b}$ & $0.41 \pm 0.04^{\mathrm{a}}$ & $0.46 \pm 0.01^{\mathrm{a}}$ & $0.44 \pm 0.04^{\mathrm{a}}$ & $0.45 \pm 0.05^{\mathrm{a}}$ & $3.32 \pm 0.26^{\mathrm{a}}$ \\
\hline
\end{tabular}

Values in the same column with different subscripts $(\mathrm{a}-\mathrm{c})$ are significantly different $(\mathrm{p}<0.05)$ from DMRT 
Fig.1 The buckwheat seeds (var. Meethey) from Sikkim

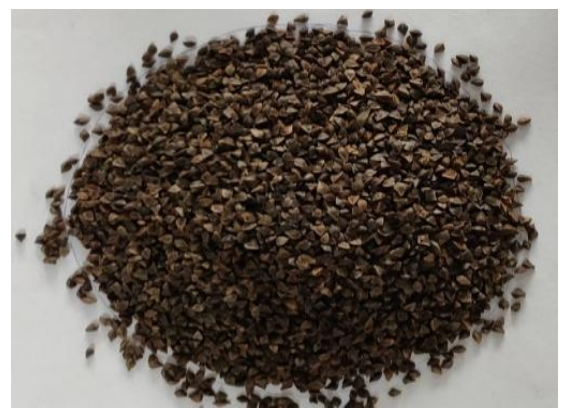

Fig.2 Measurement of the angle of repose of buckwheat seeds

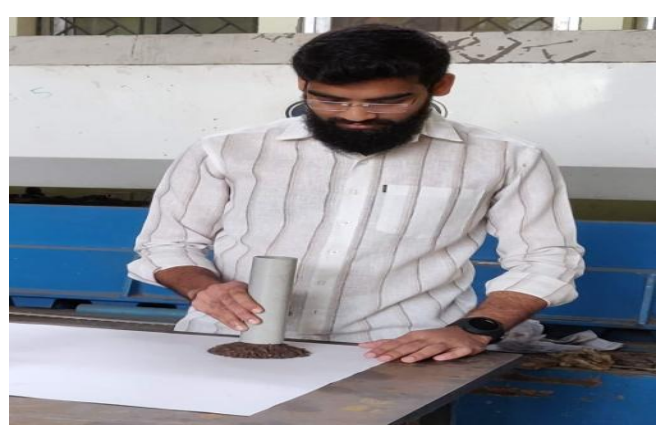

Fig.3 Tilting-top table apparatus for measurement of coefficient of static friction

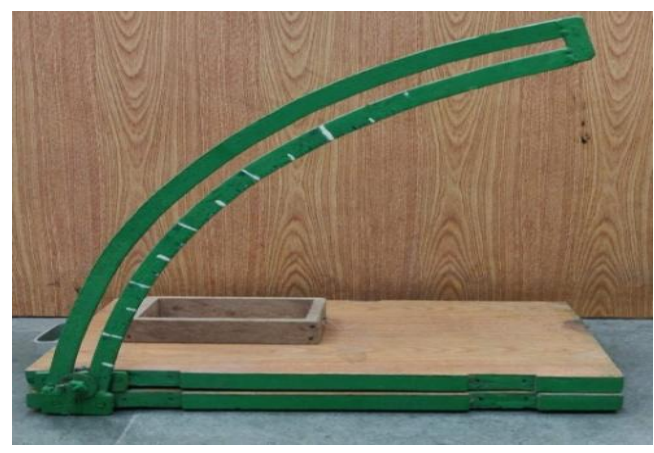

Fig.4 Experimental set-up for measurement of terminal velocity

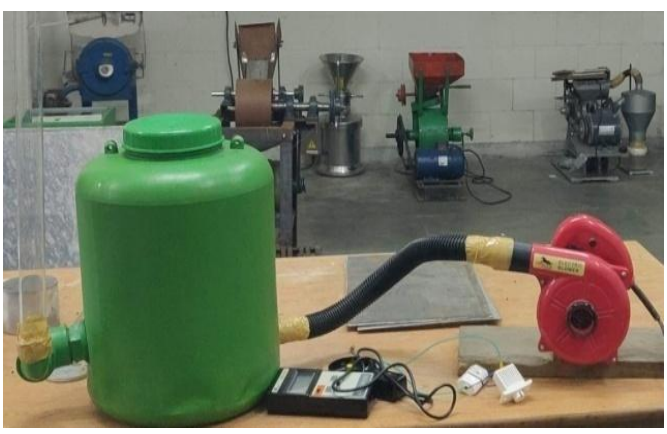


Fig.5 Effect of moisture content on dimensional properties for buckwheat seeds

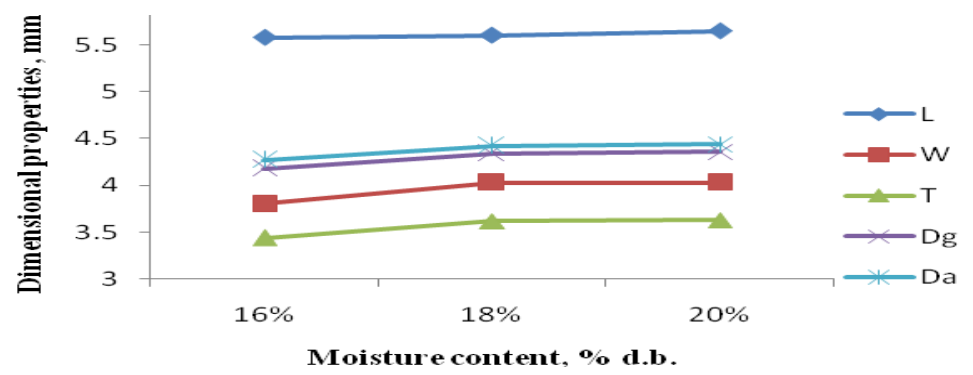

Fig.6 Effect of moisture content on surface area (A) for buckwheat seeds

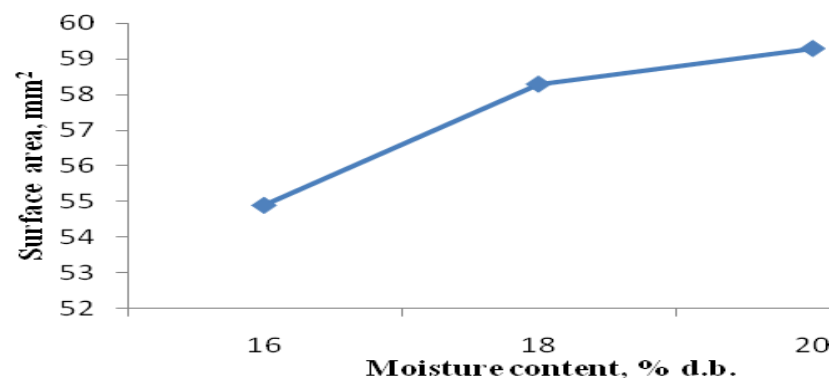

Fig.7 Effect of moisture content on thousand seeds weight $\left(\mathrm{w}_{1000}\right)$ for buckwheat seeds

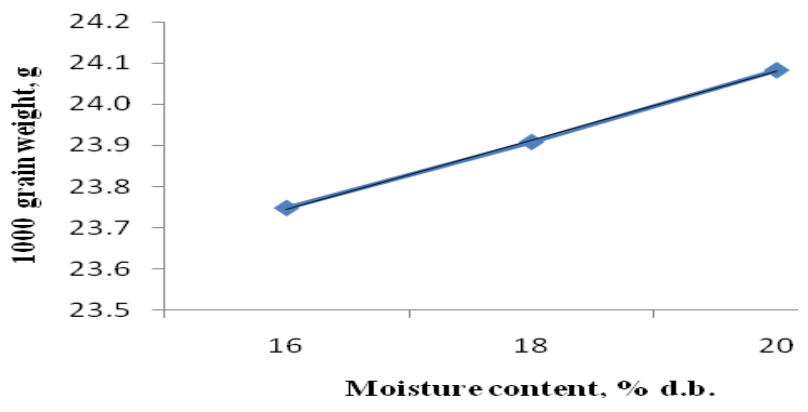

Fig.8 Effect of moisture content on bulk density $\left(\boldsymbol{\rho}_{b}\right)$ for buckwheat seeds

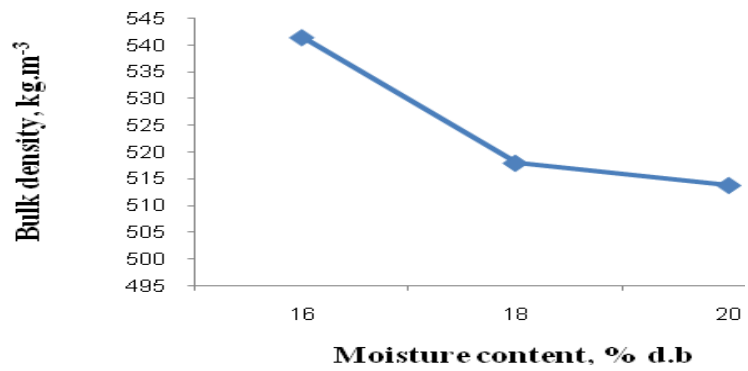


Fig.9 Effect of moisture content on true density $\left(\boldsymbol{\rho}_{\boldsymbol{t}}\right)$ for buckwheat seeds

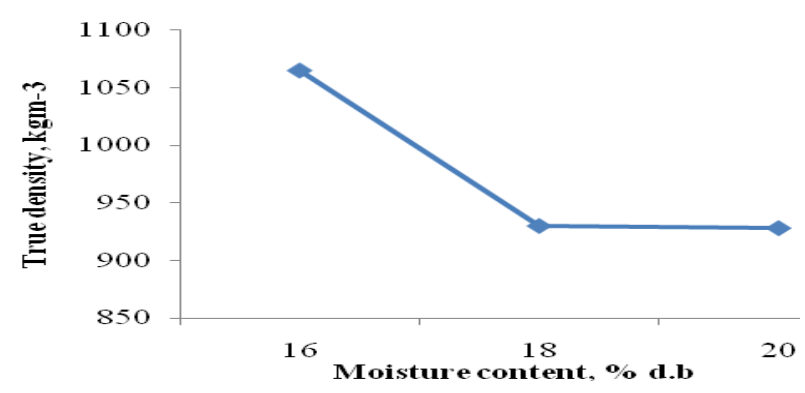

Fig.10 Effect of moisture content on porosity for buckwheat seeds

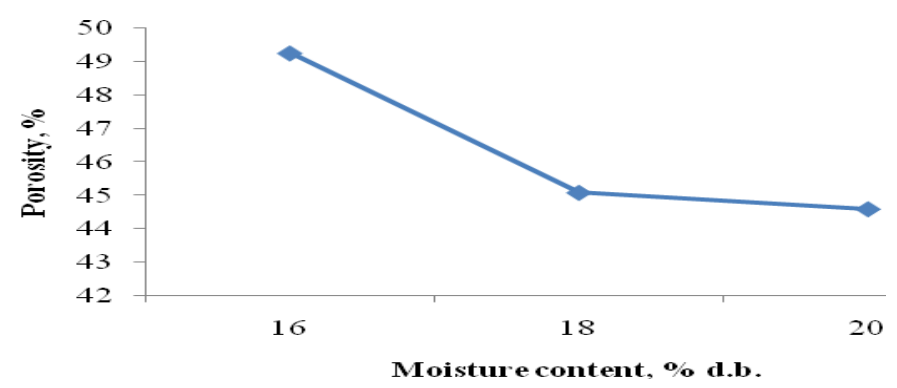

Fig.11 Effect of moisture content on angle of repose $(\boldsymbol{\theta})$ for buckwheat seeds

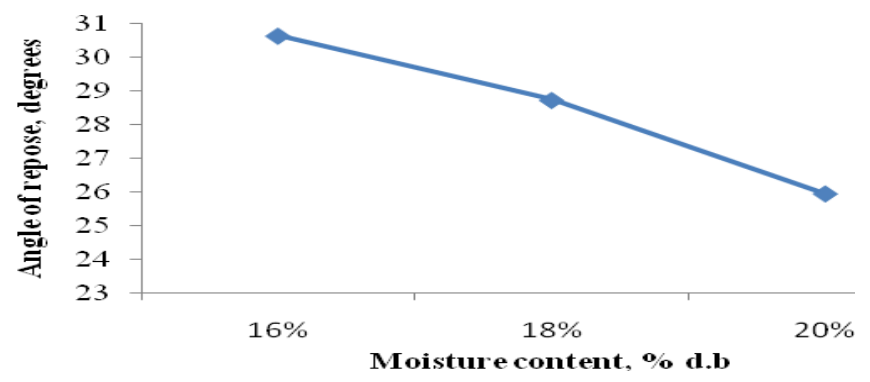

Fig.12 Effect of moisture content on terminal velocity for buckwheat seeds

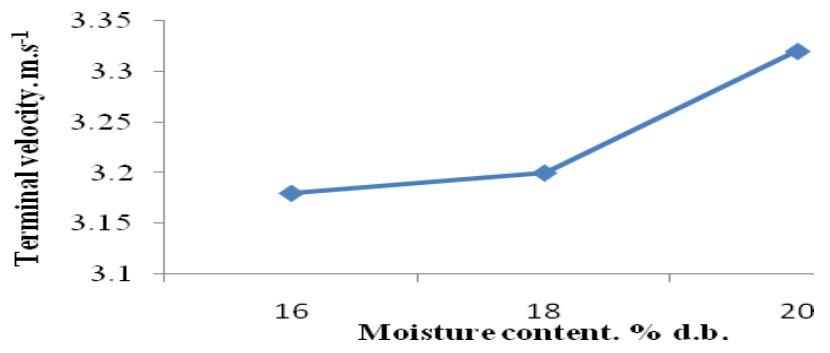




\section{Porosity}

The results of porosity of seeds are presented in Table-2. The porosity was calculated by Eq. (9), using the average values of bulk density and true density of each batch. It was observed that when moisture content increased from 16 to $20 \% \mathrm{db}$, porosity decrease significantly $(\mathrm{p}<0.05)$ from $49.26 \%$ to $45.15 \%$ as shown in Fig.10. The reason is while the seeds absorb moisture, their individual volume increases, especially due to the increment of their length (which grows more rapidly than the width and thickness); consequently, the shape of the seeds changes, and their bulk volume.

This behaviour causes the number of seeds occupying a fixed volume to decrease and thus the bulk density decreases. The addition of water to the seeds structure leads to a decrease in its true density. But, as the volume change produced by wetting the seeds differently affects their characteristic dimensions, altering mainly the length and width. The relationship between the value of porosity $(\varepsilon)$ and the moisture content can be expressed as:

$$
\varepsilon_{p}=-2.33 M+50.97 \quad\left(R^{2}=0.675\right)
$$

Similar behaviours were reported for sorghum seeds (Mwithiga and Sifuna, 2006) and niger seeds (Solomon and Zewdu, 2009).

\section{Angle of repose}

The experimental results of angle of repose with respect to moisture content are presented in Table. 3. The angle of repose decreased significant from 30.64 degrees to 25.93 degrees $(\mathrm{p}<0.05)$ when moisture increased from 16 to $20 \% \mathrm{db}$ (Fig. 11). This is probably because the surfaces of buckwheat seeds become smooth at higher moisture as compare to dry buckwheat seeds (low moisture content) which makes it easy for the seeds to slide. The angle of repose is of paramount importance in the design of openings of hoppers, side walls and storage structures (Solomon and Zewdu, 2009). Therefore, the moisture content of the seeds should be taken into account when designing such equipment and structures. The linear relationship between the angle of repose $\left({ }^{\theta}\right)$ and the moisture content can be described by the following equation:

$\theta=-2.355 M+33.14 \quad\left(R^{2}=0.988\right)$

Similar behaviour of the angle of repose with respect to moisture has been observed for sorghum seeds (Mwithiga and Sifuna, 2006).

\section{Coefficient of static friction}

The results of coefficient of friction of buckwheat seeds is presented in Table-3. The effect of moisture content in the range of $16-$ $20 \% \mathrm{db}$ on the static coefficient of friction of buckwheat seeds with the four surfaces (plywood, galvanized steel aluminium and mild steels) was found to be statistically non significant $(\mathrm{p}<0.05)$.

The static coefficient of friction was found to be $0.42-0.44,0.45-0.46,0.39-0.41$ and 0.43 0.45 for the surfaces of plywood, galvanized iron, aluminium and mild steels, respectively. The galvanized steel showed the maximum friction followed by mild steel, plywood and aluminium. The relationship between the static coefficient of friction of plywood (PW), galvanized steel (GI), aluminium (AL) and mild steel (MS) with the moisture content were represented by the following equations:

$$
\begin{array}{lc}
\mu_{a l}=0.01 M+0.383 & \left(R^{2}=0.75\right) \\
\mu_{g l}=0.005 M+0.446 & \left(R^{2}=0.75\right) \\
\mu_{p W}=0.01 M+0.4 & \left(R^{2}=0.25\right) \\
\mu_{m s}=0.01 M+0.416 & \left(R^{2}=0.75\right)
\end{array}
$$


The behaviour observed in this study was similar to that found for niger seed (Solomon and Zewdu, 2009) and okra seeds (Sahoo and Srivastava, 2002).

\section{Terminal velocity}

The experimental results of terminal velocity of buckwheat seeds at various moisture contents is reported in Table 3, the terminal velocity significantly $(\mathrm{p}<0.05)$ increased from 3.18 to $3.32 \mathrm{~ms}^{-1}$ with moisture content for Buckwheat seeds respectively. Fig. 12 depicts the variation of terminal velocity with moisture content for Buckwheat seeds. From the figures, a linear increase in terminal velocity with moisture content can be observed for seeds. Following linear regression equations can be formulated to describe the relationship between terminal velocity and moisture content of Buckwheat seeds.

$v=0.07 M+3.093 \quad\left(R^{2}=0.854\right)$

In conclusions this study, the engineering properties of buckwheat seeds were studied in relation to its moisture content within a range of $16-20 \%$ (d.b.). The dimensional properties like length, width and thickness, arithmetic mean, geometric mean, surface area, volume and sphericity showed a positive linear relationship with moisture content within the range from $16 \%$ to $20 \%$. The sphericity varied in the range between 0.75 to 0.80 indicating the shape to be closer to spherical. The seeds have similar properties to sorghum seeds (Mwithiga and Sifuna, 2006). The gravimetric properties like bulk density, true density and porosity decreased with the increase in moisture content, which was due to expansion in volume of seeds by moisture absorption. The true and bulk densities varied from 936.60 to $1067 \mathrm{~kg} \mathrm{~m}^{-3}$ and from 513.77 to 541.46 to $\mathrm{kg} \mathrm{m}^{-3}$ respectively. The densities of buckwheat are similar to other seeds like sorghum seeds (Mwithiga and Sifuna, 2006). The terminal velocities of buckwheat varied between 3.18 to $3.32 \mathrm{~m} . \mathrm{s}^{-1}$, which was closer to the value reported for sunflower seeds (Gupta and Das, 1997). The coefficient of friction was found highest in case of galvanised steel surface and lowest in case of aluminium surface.

\section{References}

Al-Mahasneh, M.A., and Rababah, T.M. (2007). Effect of moisture content on some physical properties of green wheat. Journal of Food Engineering, 79(4): 1467-1473.

Aviara, N. A., Gwandzang, M. I., and Haque, M. A. (1999). Physical properties of guna seeds. Journal of Agricultural Engineering Research,73(2), 105111.

Bart-Plange, A., and Baryeh, E. A. (2003). The physical properties of Category $B$ cocoa beans. Journal of Food Engineering, 60(3), 219-227.

Coşkun, M. B., Yalçın, İ., and Özarslan, C. (2006). Physical properties of sweet corn seed (Zea mays saccharata Sturt.). Journal of food engineering, 74(4), 523-528.

Department of Agriculture sikkim. (2019) ENVIS Hub: Sikkim Status of Environment and Related Issues. http://sikenvis.nic.in/Database/Buckw heatSikkim_4084.aspx. accessed 15dec-2020.

Gupta, R. K., and Das, S. K. (1997). Physical properties of sunflower seeds. Journal of Agricultural Engineering Research, 66(1), 1-8.

Karimi, M., Kheiralipour, K. Tabatabaeefar, A., Khoubakht, G.M., Naderi, M. and Heidarbeigi, K. (2009). The effect of moisture content on physical properties of wheat. Pakistan Journal of Nutrition, 8(1): 90-95. 
Latha R. R. and Uma N. Kulkarni. 2020. Physical and Functional Properties of Buckwheat.

Int.J.Curr.Microbiol.App.Sci. $\quad 9(04)$ : 902-907.

Mwithiga, G., and Sifuna, M.M. (2006). Effect of moisture content on the physical properties of three varieties of sorghum seeds. Journal of food engineering, 75(4): 480-486.

Sahay, K.M. and Singh, K.K. (2009). Unit operations of agricultural processing. $2^{\text {nd }}$ edition. Vikas publishing house pvt.ltd., New Delhi, pp.10-13.

Sahoo, P. K., and Srivastava, A. P. (2002). $\mathrm{PH}-$ Postharvest Technology: Physical Properties of Okra Seed. Biosystems Engineering, 83(4), 441-448.

Sologubik, C. A., Campañone, L. A., Pagano, A. M., and Gely, M. C. (2013). Effect of moisture content on some physical properties of barley. Industrial Crops and Products, 43, 762-767.

Solomon, W. K., and Zewdu, A. D. (2009). Moisture-dependent physical properties of niger (Guizotia abyssinica Cass.) seed. Industrial Crops and Products, 29(1), 165-170.

Tabatabaeefar, A. (2003). Moisturedependent physical properties of wheat. International Agrophysics, 17(4).

Tabatabaeefar, A. (2003). Moisturedependent physical properties of wheat. International Agrophysics, 17(4): 207-212.

Visvanathan, R., Palanisamy, P. T., Gothandapani, L., and Sreenarayanan, V. V. (1996). Physical properties of neem nut. Journal of Agricultural Engineering Research, 63(1), 19-25.

\section{How to cite this article:}

Mohammad Sohail, M. and Satpathy, S. K. 2021. Engineering Attributes of Buckwheat Seeds in Relation to its Moisture Content. Int.J.Curr.Microbiol.App.Sci. 10(01): 2481-2492. doi: https://doi.org/10.20546/ijcmas.2021.1001.288 